\title{
Preventive Health Care for an Endangered Species - the Physician Scientist
}

In June, 2001, the Editors of the Brazilian Journal of Infectious Diseases will participate in the postgraduate medical student course at the Federal University of Bahia, Brazil. The goal of the course is to inform young physicians about the methods for planning, conducting and communicating clinical research. As we prepare for this task, we realise that, somehow, we must communicate to these young potential investigators the additional message that medical care is facing an event in the history of medicine that would not have been predicted 40 years age - the disappearance of the species of physician termed a physician scientist [1]. We must communicate to these young investigators that the future of patient-oriented research is in their hands. We must make clear that learning from patients, as an integral part of patient care, must never disappear. We must document that what has happened in the past few decades has been a misdirection in the provision of health care, and that with the correct funding, tools and guidance they can re-establish this critical part of the health care network.

That the physician scientist is disappearing has been recorded repeatedly during the past decades $(1,2)$. However, recent articles have documented the most serious evidence of this by recording the disappearance in the United States of the time devoted to the research arm in sub-speciality training which was, and absolutely needs to continue to be, central to the existence of the physician scientist (3-6). What could be the cause of this disappearance, and what can be done to correct it?

In the 1970s the first steps in re-directing medical care were necessary and very important. Those steps included focus on the important role in health care of the Primary Care Physician - a physician that had existed in the past, but was somehow overlooked during the revolutions in medical training of the $20^{\text {th }}$ century that have led to so many important developments in health care. This alone did not create the problem, indeed, there were excellent physician scientists within the newly created Divisions of Primary Care and Family
Medicine. But the seed was planted that health care is a daily activity between a patient and a physician (the results of which are satisfied patients and efficient distribution of care at a reasonable cost). This activity included broad care of the patient in his or her environment, not in the environment of the medical speciality, or the environment of a hospital research center. This seed was nurtured by shifts in funding away from research programs toward managed care facilities and delivery of health care programs, and by the emergence of increasingly sophisticated techniques in health care leading to either prolonged periods of MD research training, or substituting of $\mathrm{PhDs}$ to accomplish the tasks. The general view emerged that clinical research is an activity conducted within pharmaceutical companies under the supervision of government regulatory organisations, or by epidemiologists within hospitals or The Centers for Disease Control, or by an increasingly rare breed of physicians who happened to develop a new test or technique. This laboratory scientist could then come to the clinic and ask to have a few patients made available to test the procedure. The physician scientist in this setting had disappeared. At the other extreme, physicians, in a field such as oncology, were in a setting where no patient existed that was not enrolled in one clinical trial or anotherthe entire field became a type of managed clinical trials endeavour. This physician was indeed doing clinical research, but it was done in a manner in which he or she became a patient organiser and data manager, not a physician scientist.

What is a physician scientist? In the past, this was a person who had special training in basic science techniques as well as patient care and who almost always had a position in a university with an academic title. He or she spent $70 \%$ of his or her time doing a mixture of basic and clinically oriented research, $15 \%$ teaching, $15 \%$ caring for patients as a consultant in a special field. The field has disappeared almost certainly because the above cited factors gradually removed the 
funding for that $70 \%$, then gradually removed the training potential for that $70 \%$, and finally removed the motivation for young physicians to seek a career in this area. The question we must now ask is, was this an accident of misplaced priorities, or the eradication of an ancient species no longer relevant to the new world of health care? The obvious opinion of the authors of this editorial is that it was an accident; one now in serious and immediate need of intensive medical care. What can be done?

First, the problem must be recognised as a misstep in priorities, not a healthy direction in medical care. Second, educational programs must be reinitiated to point out that what we are now calling clinical research is mostly not that at all, but a mixture of clinical trials management $(7,8)$, poorly formulated medical questions (9), or corporate guided massive drug intervention studies (10). Then, those same educational programs must begin to provide the tools to young investigators to ask and investigate relevant medical questions. Finally, the pressure must emerge to provide the necessary funding to allow this disappearing species to return from the brink of extinction-we have done it with the bald eagle, we should be able to do it with this species. Just as with the bald eagle we must start by protecting the species from environmental toxins, then nurture the young with special attention, then ensure they have a reasonable chance for survival in the wild.

Because the activity of the physician scientist is both a basic academic and a patient oriented one, it is appropriate that their role in the health care network can be emphasised by a new organisation for supporting and communicating their work. This new society is The Association for Patient-Oriented Research (11). Information about this society can be obtained on the internet at www.apor.org. The organisers of this group have recognised that the Society for Clinical Investigation (SCI), the society that provided the focus for this academic activity in the past, is no longer sufficiently focused on the patient-oriented aspects of clinical research (6). This is not a criticism of the SCI. It is acceptance of the reality that the decades of forcing investigators into more and more molecular oriented research has turned their attention away from the patient to such a degree that the physician scientist is now no longer a patient-oriented physician.

The small step we have taken in Brazil is the formation of this post-graduate medical student program on how to plan, conduct and communicate clinical research. The sections of the course include; 1) planning a clinical study, 2) the types of clinical trials and emerging issues regarding how they are used, 3) managing data during a clinical trial, 4) statistical issues in clinical research, 5) ethics of human experimentation, 6) publishing or presenting clinical data, and 7) special issue in medical writing. The course is based on seminars given in the past few years at several medical Congresses and summarised in a previous editorial (12). It is our belief that this step will begin to ensure that young physicians are aware of, and trained in this special and important part of health care. This course, and others like it, could be one piece of the first recommendation made by Goldstein and Brown, "reinvigorate the intellectual core of academic medicine" (6). We are aware that funding opportunities and career goal support systems are even more important than this educational objective. All members of the Brazilian Society of Infectious Disease should examine whether their institution is doing all that is necessary to provide the educational, funding, and career opportunity support for this critical part of the health care network.

\author{
Roberto Badaró \\ Editor-in-Chief BJID \\ Thomas $C$. Jones \\ Editor BJID
}

\section{References}

1. Rosenberg L.E. Physician-scientists—endangered and essential. Science 1999;283: 331-2.

2. Wyngaarden J.B. The clinical investigator as an endangered species. N Eng J Med 1979; 301:1254-9.

3. Whitcomb M.E., Walter D.L. Research training in six selected internal medicine fellowship programs. Ann Int Med 2000;133:800-7. 
4. Rosenberg L.E. Young physician-scientists: internal medicine's challenge. Ann Int Med 2000; 133:831-2.

5. Shine K.L. Encouraging clinical research by physician scientists. JAMA 1998;280:1442-4.

6. Goldstein J.L., Brown M.S. The clinical investigator: bewitched, bothered and bewildered—but still beloved. J Clin Inv 1997;99:2803-12.

7. Bohenheimer T. Uneasy alliances-clinical investigators and the pharmaceutical industry. $\mathrm{N}$ Eng $\mathrm{J}$ Med 2000;342:1539-44.

8. Weihrauch, TR. Design, management and cost of multinational trials. Europ J Clin Research 1994; 6:143-58.

9. Jones, TC. Careful evaluation of clinical and pre-clinical data is needed-not more clinical trials. Braz Jou Inf Dis 1998;2:308-10.

10. Angell, M. The pharmaceutical industry-to whom is it accountable? N Eng J Med 2000;342:1402-4.

11. Hirsch, J. An association for patient-oriented research. Ann Int Med 1999;130:1014-7.

12. Jones, TC and Badaro, R. Communicating clinical science-a challenge for us all. Braz Jou Inf Dis 1999;3:163-5. 